\title{
CHARACTERISTICS OF SCANNING CURVES OF TWO SOILS
}

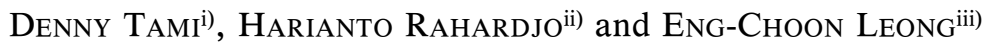

\begin{abstract}
Scanning curves of two different soils were obtained from three series of infiltration and drainage experiments on two physical models of soil slopes in the laboratory. The first slope model consisted of a fine sand layer overlying a gravelly sand layer, while the second slope model involved a silty sand layer overlying a gravelly sand layer. Each soil layer had a thickness of $200 \mathrm{~mm}$ and both slope models had an inclination angle of $30^{\circ}$. The slope models were subjected to artificial rainfalls of different intensities, followed by draining where no rainfall was applied. Various instruments were installed to continuously measure the changes in matric suction, volumetric water content and the water balance of the slope models during the experiment. Scanning curves were then constructed using the matric suction and water content data measured at the bottom, middle and top parts of the slope models and were compared with the primary drying and primary wetting soil-water characteristic curves that were measured separately. It was found that the scanning curves followed the primary wetting curve during the adsorption process and then followed the primary drying curve during the desorption process. During the transition period, over which the scanning curve moved from the primary drying curve to the primary wetting curve (or vice versa), the path of the scanning curve had a relatively flat slope as compared to the slope of the primary curves, and sometimes it was almost horizontal. However, the slope and the path of the scanning curves were found to be similar for the cases with similar initial conditions.
\end{abstract}

Key words: hysteresis, scanning curves, soil-water characteristic curve, unsaturated soils (IGC: D4/E6/E7)

\section{INTRODUCTION}

Hysteresis in the relationship between negative porewater pressure or matric suction and water content is commonly observed for many unsaturated soils in the laboratory. The path of the matric suction versus water content plot for the desorption process (i.e., decrease in water content) and the path for the adsorption process (i.e., increase in water content) are different, as a result of hysteresis. This phenomenon can be described using the 'ink bottle effect'. When an empty capillary tube is placed in a water bath, the water table within the tube will rise up until water reaches an equilibrium state. In this case, the wetting cycle occurs. On the other hand, when the tube is filled up with water, water will be drained out until it reaches an equilibrium state. The case refers to the drying cycle. The equilibrium state achieved through a wetting cycle and through a drying cycle is the same when the tube is straight. However, when the tube has an expanded space in the middle, the equilibrium state may be different. The expanded portion of the tube is empty in the wetting cycle, while it is filled with water in the drying cycle. As a result, the water contents obtained from the wetting and drying cycles are not the same. The above capillary tube analogy applies to soil conditions in nature due to its non-uniform pore size distribution. There are three specific mechanisms causing hysteresis (Iwata et al., 1995): (i) different pore sizes of the soil in different moisture states, (ii) adsorbed water on clay surfaces and (iii) different contact angles between the air-water interface and the soil solid surface.

The plot of water content or degree of saturation versus matric suction of soils is known as the soil-water characteristic curve or SWCC. The water content of the soil decreases as its matric suction increases following a drying (desorption) path and the reverse cycle will increase the water content along a wetting (adsorption) path. The soil-water characteristic curve is hysteretic; that is, for a specific matric suction, the water content on a wetting curve is always lower than that found on a drying curve. The drying curve that starts from saturation is commonly called the primary drying curve (Fig. 1). Similarly, the wetting curve that starts from a dry (or relatively low water content) condition is commonly called the primary wetting curve. The region enclosed within the primary drying and primary wetting curves is called the hysteresis region. Besides the primary curves (or bounding curves), the "scanning" curves are series of soil-water characteristic curves that start from a particular condition that is neither saturated nor dry. These

i) Formerly Research Scholar, School of Civil and Environmental Engineering, Nanyang Technological University, Singapore.

ii) Professor and Vice Dean, ditto (chrahardjo@ntu.edu.sg).

iii) Associate Professor and Head of Geotechnical and Transportation Engineering Division, ditto.

The manuscript for this paper was received for review on November 17, 2005; approved on July $26,2006$.

Written discussions on this paper should be submitted before September 1, 2007 to the Japanese Geotechnical Society, 4-38-2, Sengoku, Bunkyo-ku, Tokyo 112-0011, Japan. Upon request the closing date may be extended one month. 


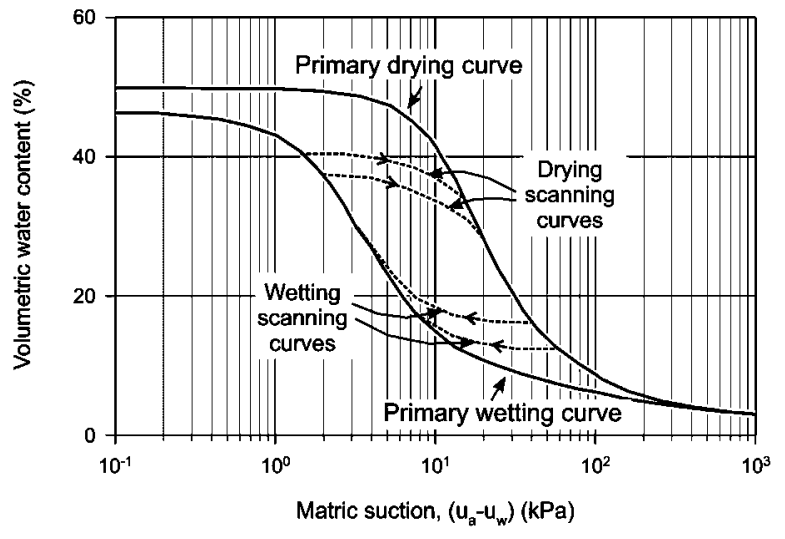

Fig. 1. Primary soil-water characteristic curve and scanning curves

scanning curves are different depending on the state of the reversal point in the process of successive wetting and drying (see Fig. 1).

Researchers in the soil physics field have tried to measure and construct the primary and scanning curves of a porous specimen in the laboratory for a long time (e.g., Topp and Miller, 1966). Topp and Miller (1966) measured the scanning curves for a poorly graded glass bead sample. Many other researchers have measured the relationships between water content and pore-water suction for different soils (e.g., Talsma, 1970; Watson et al., 1975; Topp, 1971; Poulovassilis, 1970; Poulovassilis and Childs, 1971; Vachaud and Thony, 1971; Nimmo and Miller, 1986; Hogarth et al., 1988, Feng and Fredlund, 1999; Pham et al., 2003). However, their main concern was the primary or bounding curves, rather than the scanning curves, in studying the hysteresis phenomena in unsaturated soils.

A number of simple analytical solutions have also been developed to provide forms for the primary curves that exhibit hysteresis. In the early stage, the independent domain theory was used to model the hysteresis of water in soil. The soil pores are viewed as independent domain that have only two states, either full or empty, and each domain has two corresponding matric suctions for each state. Poulovassilis (1970) reported a theory that is applicable to glass beads and sands. However, other researches observed considerable discrepancies between predicted and observed scanning curves (Topp and Miller, 1966; Topp, 1971; Talsma, 1970; Vachaud and Thony, 1971). Mualem (1974) then proposed a conceptual model of hysteresis that simplifies the computational procedures but gives better agreement with observations. Subsequently, Parlange (1976) proposed a model that corresponds to a special case of Mualem's hypothesis, which requires a knowledge of only one primary curve. Hogarth et al. (1988), Viaene et al. (1994), Liu et al. (1995), Si and Kachanoski (2000) and Braddock et al. (2001) applied the classical Brooks and Corey (1964) and van Genuchten (1980) soil-water characteristic curve models to the Parlange hysteresis model and reported that the predicted curves agree with the laboratory observation.
The focus of this paper is to compare and analyse scanning curves that were obtained from a series of infiltration and drainage tests on a physical model of soil slopes in the laboratory. Both wetting and drying scanning curves of two different soils (i.e., fine sand and silty sand) are presented. Scanning curves measured at the bottom, middle and top parts of each slope model were constructed and compared with the primary drying and primary wetting curves that were measured independently, to show the processes (i.e., drying or wetting) in an unsaturated slope under different flux conditions. The differences observed in the scanning curve of these two soils as well as the characteristic of the scanning curve are analysed and discussed.

\section{MATERIALS AND METHODS}

\section{Description and Parameters of Soils}

Two-layer soil slope models were constructed in the laboratory to elucidate the mechanism of water flow in unsaturated slopes. The soil slope consisted of relatively fine soil over relatively coarse soil layers. Silty sand and fine sand were used as relatively fine materials, while gravelly sand was selected as a relatively coarse material. The silty sand is a local residual soil from the Bukit Timah formation (Public Works Department, 1976). Bukit Timah Granitic residual soils vary from silty or clayey sands to silty or sandy clays, depending on the degree of weathering, but are commonly sandy clayey silts (Rahardjo, 2000). The fine sand was a sand used in the Changi reclamation projects. The light grey to white gravelly sand was crushed from fresh granite. These three soils were selected to provide two-layer soil slope models with contrasting hydraulic parameters.

The silty sand was well-graded with a coefficient of uniformity, $U_{\mathrm{c}}$ of 1120 and a coefficient of curvature, $C_{\mathrm{c}}$ of 1.58 , and was categorized as an SM soil according to the Unified Soil Classification System (USCS). The fine sand was poorly-graded $\left(U_{\mathrm{c}}\right.$ of 2.1 and $C_{\mathrm{c}}$ of 0.89$)$. The gravelly sand was a poorly-graded, uniform soil having $50.1 \%$ of grains passing the No. 4 ASTM $(4.75 \mathrm{~mm})$. Both the fine sand and gravelly sand were categorized as poorly-graded sand (SP according to the USCS). The saturated coefficients of permeability, $k_{s}$, for the silty sand (at a dry density of $1.47 \mathrm{Mg} / \mathrm{m}^{3}$ ), the fine sand (at a dry density of $1.56 \mathrm{Mg} / \mathrm{m}^{3}$ ), and the gravelly sand (at a dry density of $1.62 \mathrm{Mg} / \mathrm{m}^{3}$ ) were $2.2 \times 10^{-6}, 2.7 \times 10^{-4}$ and $7.6 \times 10^{-2} \mathrm{~m} / \mathrm{s}$, respectively. The dry densities of the soils in the permeability tests were controlled to be similar to the dry densities used in the slope models. The basic parameters of the soils used in this study are shown in Table 1.

The primary drying curves of the soil-water characteristic curves of the soils were measured using a Tempe pressure cell (Model 1405 B01M3-3, Soilmoisture Equipment Co., USA), while the primary wetting curves were measured using capillary rise tubes. The Tempe pressure cell operates on the same principle as the pressure plate apparatus as described in ASTM D 2325-68 
Table 1. Index and hydraulic parameters of the soils

\begin{tabular}{|c|c|c|c|c|}
\hline \multirow[b]{2}{*}{ Properties } & \multirow[b]{2}{*}{ Unit } & \multicolumn{3}{|c|}{ Soils } \\
\hline & & $\begin{array}{c}\text { Gravelly } \\
\text { sand }\end{array}$ & $\begin{array}{l}\text { Fine } \\
\text { sand }\end{array}$ & $\begin{array}{l}\text { Silty } \\
\text { sand }\end{array}$ \\
\hline Unified Soil Classification & & SP & SP & $\mathrm{SM}$ \\
\hline Specific gravity & & 2.62 & 2.65 & 2.59 \\
\hline \multicolumn{5}{|l|}{ Grain-size analysis results } \\
\hline$D_{60}$ & $\mathrm{~mm}$ & 5.15 & 0.35 & 0.56 \\
\hline$D_{30}$ & $\mathrm{~mm}$ & 3.68 & 0.23 & 0.021 \\
\hline$D_{10}$ & $\mathrm{~mm}$ & 2.73 & 0.17 & 0.0005 \\
\hline Coefficient of uniformity, $C_{\mathrm{u}}$ & & 1.9 & 2.1 & 1120 \\
\hline Coefficient of curvature, $C_{\mathrm{c}}$ & & 0.96 & 0.89 & 1.58 \\
\hline Gravel content $(>4.75 \mathrm{~mm})$ & $\%$ & 49.9 & 0 & 0.2 \\
\hline Fines content $(<0.075 \mathrm{~mm})$ & $\%$ & 0 & 0.8 & 38.9 \\
\hline \multicolumn{5}{|l|}{ Atterberg limits } \\
\hline Liquid limit & $\%$ & - & - & 48 \\
\hline Plastic limit & $\%$ & - & - & 27 \\
\hline Plasticity index, PI & $\%$ & - & - & 21 \\
\hline \multicolumn{5}{|l|}{ Relative density test results } \\
\hline Minimum dry density, $\pi_{\mathrm{d} \min }$ & $\mathrm{Mg} / \mathrm{m}^{3}$ & 1.42 & 1.34 & 1.21 \\
\hline Maximum dry density, $\pi_{\mathrm{d} \max }$ & $\mathrm{Mg} / \mathrm{m}^{3}$ & 1.71 & 1.61 & 1.56 \\
\hline Maximum void ratio, $e_{\max }$ & & 0.845 & 0.978 & 1.140 \\
\hline Minimum void ratio, $e_{\min }$ & & 0.532 & 0.646 & 0.660 \\
\hline \multicolumn{5}{|l|}{ Compaction test results } \\
\hline Maximum dry density, $\pi_{\mathrm{d} \max }$ & $\mathrm{Mg} / \mathrm{m}^{3}$ & - & - & 1.85 \\
\hline Optimum water content, $w_{\text {opt }}$ & $\%$ & - & - & 16 \\
\hline Saturated permeability, $k_{\mathrm{s}}$ & $\mathrm{m} / \mathrm{s}$ & $7.6 \times 10^{-2}$ & $2.7 \times 10^{-4}$ & $2.2 \times 10^{-6}$ \\
\hline at dry density, $\pi_{\mathrm{d}}$ & $\mathrm{Mg} / \mathrm{m}^{3}$ & 1.62 & 1.56 & 1.47 \\
\hline
\end{tabular}

(1994) and the method using capillary rise tubes can be found in Lambe (1951) and Fredlund and Rahardjo (1993). The measured volumetric water content and the corresponding matric suction for both the primary drying and primary wetting soil-water characteristic curves were fitted using the Fredlund and Xing (1994) equation. The correction factor for the fitting equation, $C(\psi)$, was set to 1 as recommended by Leong and Rahardjo (1997). The main purpose of the curve fitting was to obtain smooth and full-range primary drying and wetting soil-water characteristic curves. The dry densities of the soils used in the tests for the determination of the primary soil-water characteristic curves were controlled to be similar to the dry densities used in the slope models.

The grain size distribution curves of the soil samples are shown in Fig. 2, while the primary drying and the primary wetting soil-water characteristic curves are presented in Fig. 3 .

\section{Laboratory Experiments}

Soil slope models were designed and constructed in the laboratory to study the mechanism of water flow in unsaturated soil slopes. The two-layer soil slope models consisted of a $20-\mathrm{cm}$ thick layer of relatively fine soil (i.e., fine sand or silty sand) over a $20-\mathrm{cm}$ thick relatively coarse soil layer (i.e., gravelly sand), and were constructed inside an infiltration box and subjected to simulated rainfalls with varying intensities and durations. The changes in matric suction and volumetric water content at various locations along the slope model, as well as changes in water balance, were monitored continuously during the experiments. From the matric suction and the

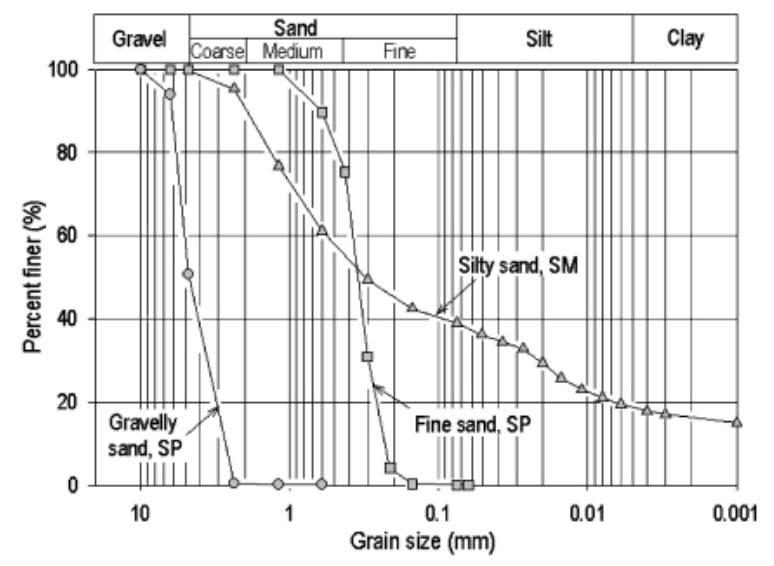

Fig. 2. Particle size distribution curves of soils used in the study

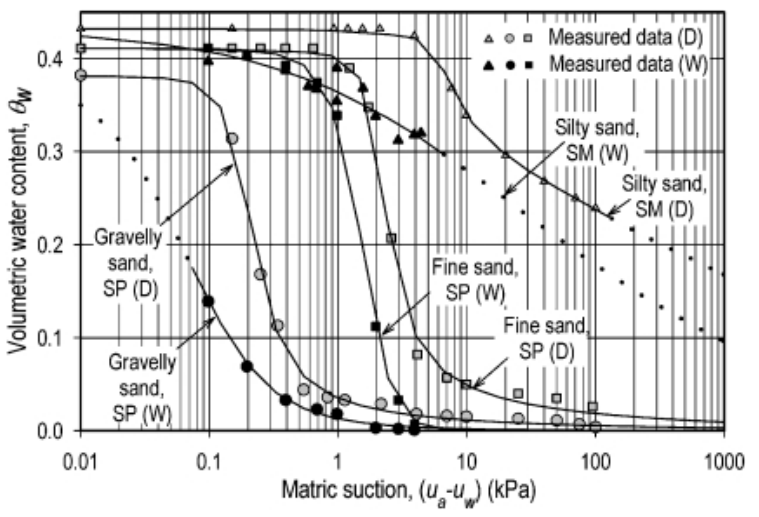

Fig. 3. Primary soil-water characteristic curves of soils used in the study ( $W$ and $D$ indicate wetting and drying data, respectively)

volumetric water content data, the scanning curves developed during the experiments were constructed.

\section{Physical Model of Soil Slope}

The general arrangement of the physical model is shown in Fig. 4. The main components of the physical model are: an infiltration box, a rainfall simulator, a water circulation system and measuring devices. The infiltration box was $2.45 \mathrm{~m}$ in length, $2 \mathrm{~m}$ in height and $0.4 \mathrm{~m}$ in width. The infiltration box is supported by a steel table, which also functions as an enclosure for a water sump tank (which provides the rainfall and recycles it using the water circulation system) and a water pump. The rainfalls were applied through a rainfall simulator located on top of the infiltration box. The intensities and durations of the simulated rainfalls were controlled using a magnetic flowmeter, while the amount of water flows from the model was measured using electronic weighing balances. A detailed explanation of the apparatus and test procedures adopted are given in Tami et al. (2004).

\section{Measuring Devices}

A tensiometer-pressure transducer system and time domain reflectometry (TDR) were employed to continuously measure the changes in matric suction and 


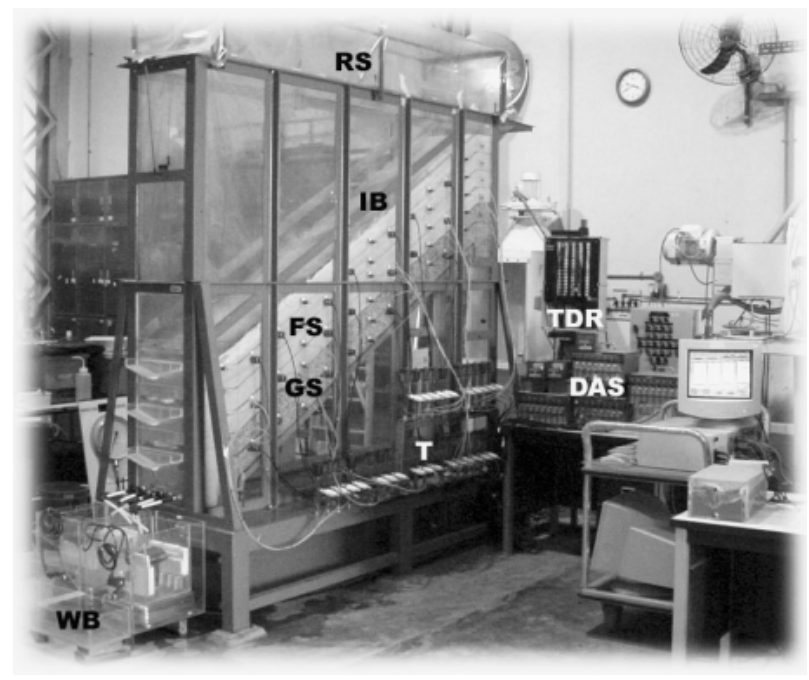

Fig. 4. A view of laboratory set-up for the experiment (RS: rainfall simulator, IB: infiltration box, DAS: data acquisition system, WB: collection tank above electronic weight balance, TDR: Trase system and accessories, $T$ : tensiometer body tube and pressure transducer attached, FS: fine sand layer, GS: gravelly sand layer (magnetic flow meter not shown in photograph)

volumetric water content along the slope model during the experiments. The experimental data were stored in a personal computer via a data acquisition system, for subsequent analyses.

\section{Tensiometer-Pressure Transducer}

Small-tip tensiometers, with flexible coaxial tubing, from the Soilmoisture Equipment Corp. were used in this study. The pressure transducer can measure negative and positive pressures (i.e., -100 to $75 \mathrm{kPa}$ ) and was attached to each of the tensiometers for automatic data recording. The pressure transducers were calibrated against water pressure and each pressure transducer reading was rechecked or verified again prior to the experiments.

During a trial run prior to the experiments, it was observed that the tensiometer-pressure transducer system used could give almost an instantaneous response (i.e., within one minute) to the changes in matric suction in the sandy soils and needed a maximum five minutes to measure matric suction in the silty sand soils. The difference in response time of tensiometer-pressure transducer system was due to the difference in water content of the fine sand and silty sand used in the slope model at the time of the trial run. The response time of the tensiometer-pressure transducer system decreased as the degree of saturation of the soils increased.

It was observed that the tensiometer-transducer system used exhibited daily fluctuations of up to $1 \mathrm{kPa}$. The magnitude and pattern of the daily fluctuations of the pressure transducers' readings were similar for each data logger. Therefore, these fluctuations could be eliminated by using a reference transducer in each data logger. The readings of the other pressure transducers were corrected based on the readings of the reference pressure transducer

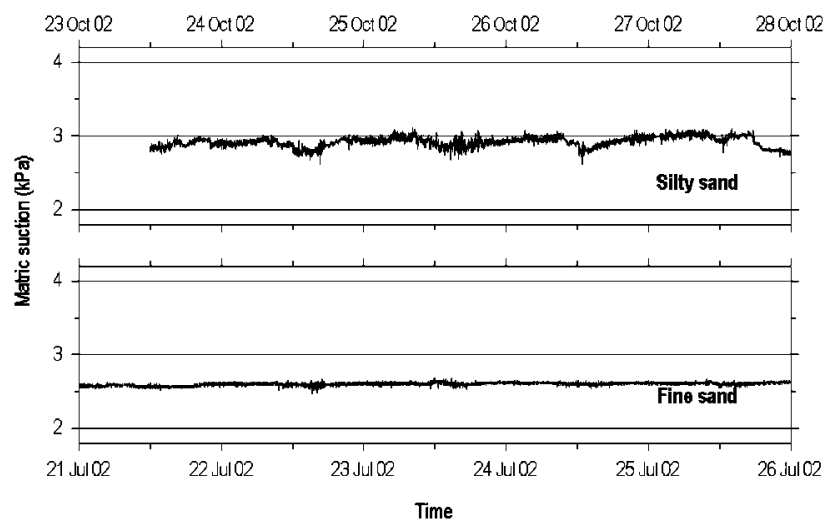

Fig. 5. Daily fluctuation of tensiometer readings in silty sand and fine sand after the correction made

and as a result, the accuracy of the tensiometer-transducer system used could reach $0.1 \mathrm{kPa}$.

This correction was especially effective and useful in a long-term experiment or in a steady-state experiment, when the change in the matric suction of the slope model was not large. Without the correction, it would be difficult to analyze the experimental data since the changes in matric suction observed could be at similar order to the fluctuations. Figure 5 presents a relatively small daily fluctuations of matric suctions from the tensiometer-pressure transducer readings in the fine sand and the silty sand after applying the correction.

\section{Time Domain Reflectometry (TDR)}

The TDR system used in this study was manufactured by Soilmoisture Equipment Corp. The system consists of a step-pulse generator (i.e., namely Trase BE) that comes with a 4-megabyte memory card for data storage purposes, a coaxial cable and three-rod standard buriable wave-guides with rod dimensions of $3 \mathrm{~mm}$ in diameter and $200 \mathrm{~mm}$ in length. A 76-channel multiplexer enclosure and two 16-channel TDR switching boards were also used to allow simultaneous measurements of volumetric water content for up to 31 wave-guides.

The relationship between the dielectric constant $\left(K_{\mathrm{a}}\right)$ and the volumetric water content $\left(\theta_{\mathrm{w}}\right)$ of soil for the standard buriable wave-guide used was provided by the TDR's manufacturer and it was already integrated in the Trase BE. The maximum deviation of the measurement is $\pm 2 \%$ of the volumetric water contents (Soilmoisture, 1996). In this study, the accuracy of the TDR used in the measurements was verified prior to the experiments. The volumetric water contents of soils measured by the TDR were compared with the volumetric water contents measured by the oven-drying method. This verification test was conducted on all soils used in the study over the range of water contents. Figure 6 presents the verification curve of the TDR measurement. Unlike the tensiometertransducer reading, the TDR reading did not exhibit daily fluctuations.

A total of 18 tensiometers was installed along 6 crosssections with 3 tensiometers located in each row. Similar- 


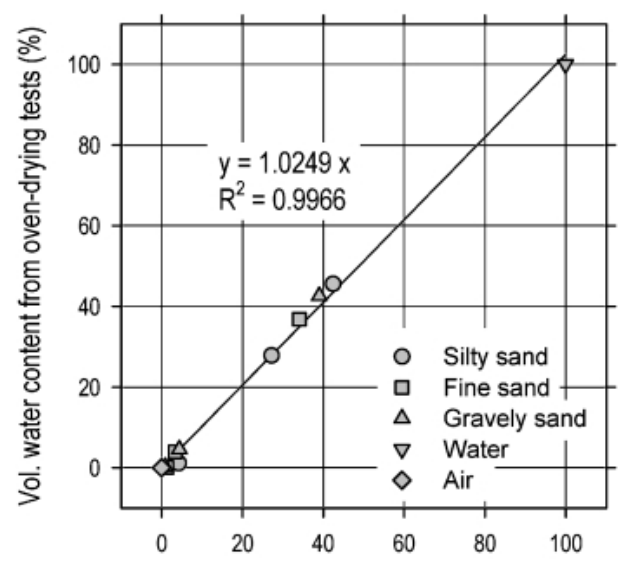

Vol. water content from TDR measurements (\%)

Fig. 6. Verification of TDR measurement against oven-drying method

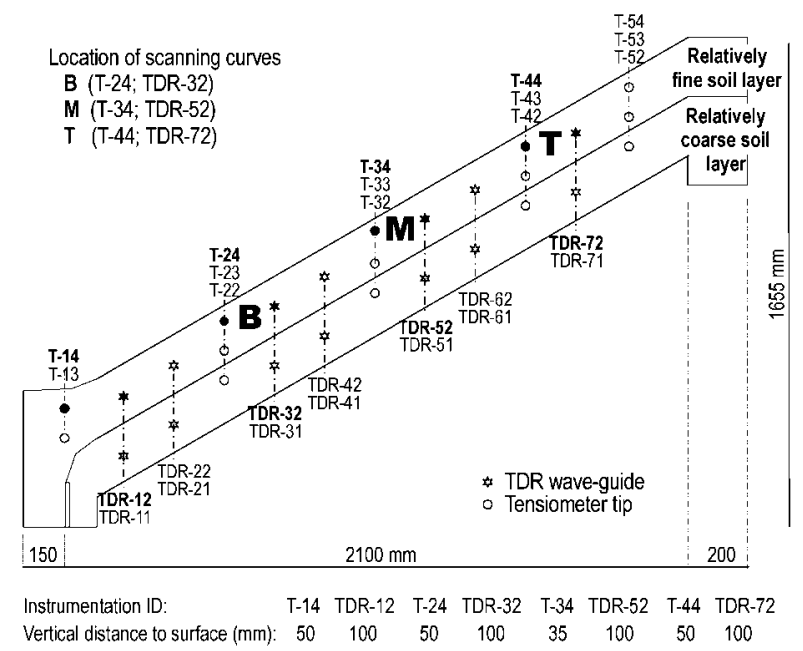

Fig. 7. Location of measuring devices and the points where the scanning curves were measured $(B, M$ and $T$ indicate bottom, middle and top parts of the model)

ly, a total of 14 TDR wave-guides was installed along 7 cross-sections with 3 TDR wave-guides located in each cross-section. The arrangement of the tensiometer tips and the TDR wave-guides along the slope model is shown in Fig. 7.

\section{Construction of the Scanning Curves}

The matric suction and volumetric water content data recorded by the tensiometers and TDRs, respectively, from locations at close proximity are plotted together on the same graph. This plot can be used to investigate the path along the soil-water characteristic curve that was followed during the experiment. These paths define the scanning curves for the soil-water characteristic curve.

Three sets of scanning curves from the experimental data from the bottom, middle and top parts of the slope model were constructed for each series of experiments. Difficulty was encountered in measuring the matric suction in the relatively coarse soil layer (i.e., gravelly sand) and the tensiometers gave erroneous readings.
It was suspected that the water phase in the gravelly sand was likely discontinuous due to the low water content of the gravelly sand layer (i.e., 3 to $4 \%$ at the initial stage of experiment). Once the tensiometer lost contact with the water phase in the soil, the tensiometer reading would become unreliable. The relatively large size of the gravelly sand grains also contributed to the poor performance of the tensiometers since good contact between the gravelly sand grains and the tensiometer tip would not be achieved. As a result, only the scanning curves from the relatively fine soil layer (i.e., fine sand or silty sand) were available from the experiments.

For the scanning curves located at the bottom part of the model, the matric suction data measured by tensiometer T-24 and the volumetric water content data measured by TDR-32 were used. Similarly, to construct the scanning curves located at the middle and top parts of the model, the matric suction data measured by tensiometers T-34 and T-44 and the volumetric water content data measured by TDR-52 and TDR-72 were used, respectively. The tensiometers located along row-4 (i.e., T-24, T-34 and T44) were selected, instead of those located along row-3 (i.e., T-23, T-33 and T-43), because their locations were closer to the locations of the corresponding TDRs (i.e., TDR-32, TDR-52 and TDR-72). The locations where the scanning curves measured are presented in Fig. 7 as indicated by B, M and T for the bottom, middle and top part locations of the model, respectively. The tensiometers and the TDRs used were also highlighted in bold type.

As can be seen from Fig. 7, the locations of the tensiometers used to construct the scanning curves are lower than the locations of the corresponding TDRs. However, in terms of vertical distance to the surface of the slope model, the tensiometer locations are nearer to the surface of the model compared to the corresponding TDRs locations. These arrangements of the locations of the tensiometers and the TDRs were consistent for the three sets of scanning curves analysed in this paper. The error that could be involved in the construction of the scanning curves due to the different locations of the tensiometers and the TDRs are discussed in Error in Estimation of Scanning Curves due to the Different Locations of Tensiometer Tips and TDR Wave-Guides of this paper.

\section{RESULTS AND DISCUSSION}

The experimental data from the two infiltration tests are presented and analyzed in this paper in order to study the characteristics of the scanning curves for fine sand and silty sand. The infiltration tests involved both adsorption (i.e., application of simulated rainfall for a given intensity and duration) and desorption (i.e., no application of simulated rainfall while infiltrating water was allowed to drain out from the slope model). Hence, the volumetric water contents of the soils increased during the adsorption process and decreased during the desorption process. 
Prior to the experiment, the slope model was left exposed to ambient conditions for about one week after the previous infiltration tests had ended. This was done to minimize the effect of the previous test on the current test as well as to obtain a relatively dry initial condition for the model. Each infiltration test comprised of three stages with different rainfall loading being applied. In each stage, a twenty-four hour simulation was conducted, starting with 5 hours of adsorption (i.e., application of rainfall or wetting process) and subsequently followed by 19 hours of desorption (i.e., no rainfall applied and water was allowed to drain from the model or drainage process). The average intensities of the simulated rainfalls applied during Stages I, II and III of the first infiltration test were $8.1,19.2$ and $8.0 \mathrm{~mm} / \mathrm{h}$, respectively. Similarly, in the second infiltration test the average intensities of the simulated rainfall applied were 7.8, 15.8 and $7.5 \mathrm{~mm} / \mathrm{h}$ during Stages I, II and III, respectively. The duration of the application of the simulated rainfalls in the second infiltration test was the same as in the first infiltration test. Figure 8 shows the intensities and durations of the simulated rainfalls applied in the first

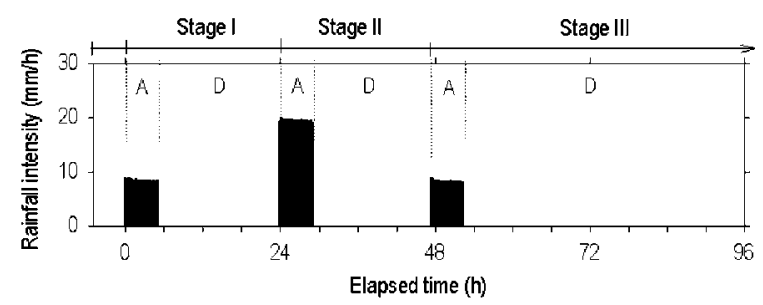

Fig. 8. Intensities and durations of simulated rainfall applied in the first and second infiltration test series infiltration test, where $\mathrm{A}$ and $\mathrm{D}$ indicate adsorption and desorption processes, respectively. The draining process of Stage III (i.e., Stages III-D) for the experiment on the slope model consisting of fine sand over gravelly sand (i.e., the first infiltration test) was carried out for about 60 hours. However, due to the difficulty of draining the silty sand (i.e., the silty sand has a significantly lower coefficient permeability compared with the fine sand), Stage III-D consisting of silty sand over gravelly sand (i.e., the second infiltration test) was continued up to 12 days.

The underlain gravelly sand layer used in the slope model, apparently acts as a capillary break similar to that in a capillary barrier system (i.e., relatively fine-grained layer over relatively coarse-grained layer). Under certain circumstances, the relatively coarse-grained layer prevents downward water movement. In the infiltration tests presented in this paper, no breakthrough (i.e., penetration of water to the relatively coarse-grained layer) was observed as the matric suctions and water contents of the gravelly sand layer remained unchanged throughout the tests.

\section{General Shapes of the Scanning Curves \\ Scanning Curves of Fine Sand}

Figure 9 shows three sets of scanning curves measured in the fine sand at locations B, M and T (see Fig. 7). The solid symbols (i.e., diamonds, circles or squares) represent the experimental data from the adsorption process, while the open symbols represent the experimental data from the desorption process. The time interval between measurements was 5 minutes. The primary drying and the primary wetting soil-water characteristic curves as obtained from independent measurements (i.e.,

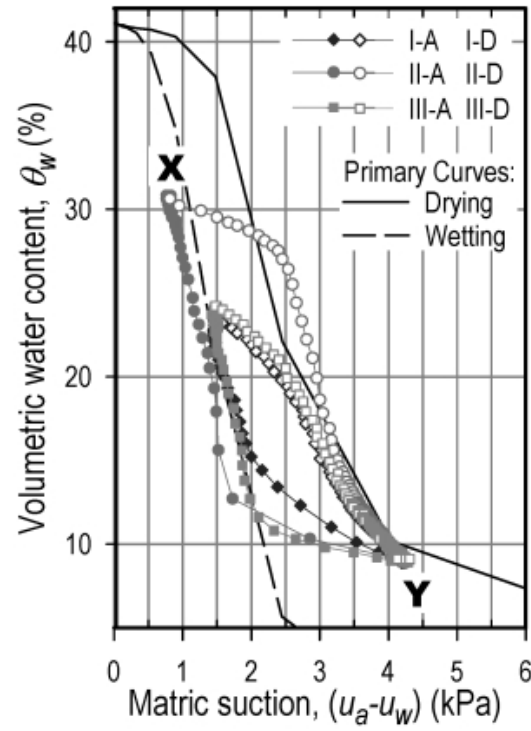

(a) at bottom part of the model (location B)

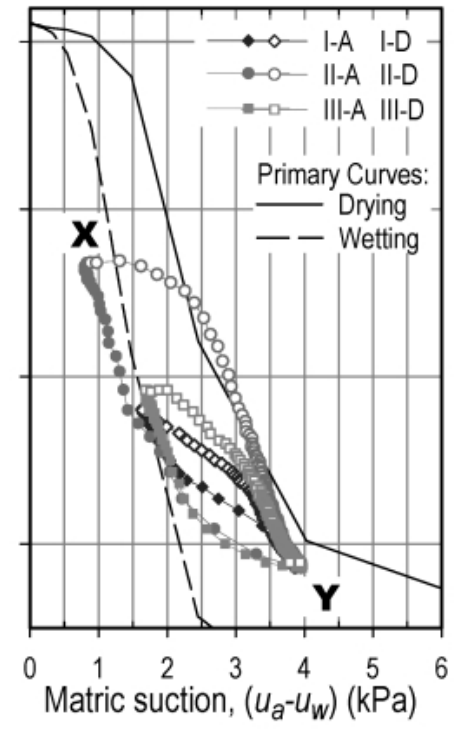

(b) at middle part of the model (location M)

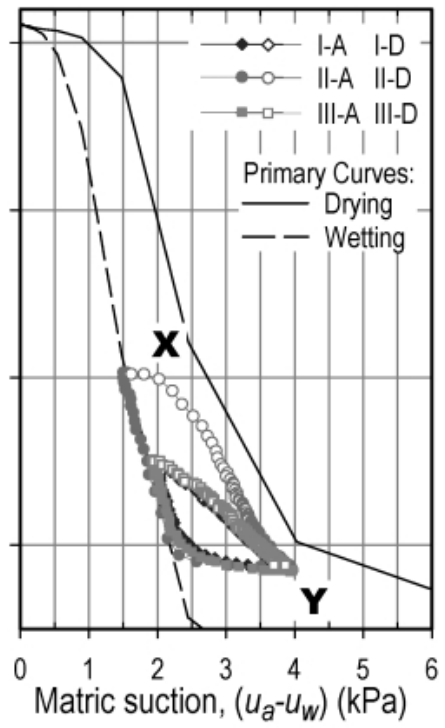

(c) at top parts of the model (location T)

Fig. 9. Primary soil-water characteristic and scanning curves measured in the fine sand during the first infiltration test series (I, II, III indicate the stages, while $A$ and $D$ indicate adsorption and desorption, respectively) 
Tempe pressure cell test or capillary rise test) are also presented in Fig. 9.

The scanning curves followed the primary wetting soilwater characteristic curve during the adsorption process and followed the primary drying soil-water characteristic curve during the desorption process (see Fig. 9). Since the adsorption experiments were started from a dry condition, the scanning curve was initiated from the primary drying curve. At the initial state of the experiments, the scanning curves first moved from the primary drying curve to the primary wetting curve, however the path did not move horizontally since both matric suctions and volumetric water contents changed. The scanning curves then followed the path of the primary wetting curve to some extent, depending on the intensities of the simulated rainfall applied. It was also observed that the rates of matric suction and volumetric water content change decreased as the scanning curve data points became closer to each other since the acquisition time between two data points was the same.

Once the simulated rainfall ended, the scanning curves moved back to the primary drying curve. However, the development of these drying scanning curves was slower compared with the development of the wetting scanning curves, as the plotted data were set in a closer distance in the drying curves. This observation indicated that the decrease in matric suction and the increase in volumetric water content occurred rapidly during the adsorption process. In contrast to the rapid changes in matric suction and volumetric water content observed in the adsorption process, the increase in matric suction and the decrease volumetric water content observed during the desorption process occurred gradually.

The difference in the rate of development of the scanning curves between those observed on adsorption and those observed on desorption was related to the changes in the coefficient of permeability of the soils. In the adsorption process, the permeability increased during the test since the matric suction decreased and this caused a rapid increase in the velocity of water flow in the soil. On the other hand, the permeability decreased during the desorption process since the matric suction increased and this caused a slowing down of water movement along the slope model. As a result, the changes in matric suction occurred gradually in the desorption process.

It was also observed that the matric suctions and volumetric water contents in the fine sand returned to their initial values (i.e., prior to the application of the simulated rainfall) after 19 hours of drainage. As a result, during the twenty-four hour simulation, complete wetting and drying scanning curves could be obtained.

The scanning curves from the first and the third stages (see Fig. 8) were almost the same for both adsorption and desorption, while those from the second stage varied more widely but still exhibited the same trend. The intensity of the simulated rainfall was higher during the second stage than those applied in the other two stages, thereby producing a longer path for the scanning curves. The matric suction and the volumetric water content changes in the second stage were noticeably higher than those in the other stages (see Fig. 9).

If the scanning curves from different locations are compared, it can be seen that those measured at location $B$ have the largest matric suction and volumetric water content variations, while those measured at location $\mathrm{T}$ have the smallest matric suction and volumetric water content variations. Even though the simulated rainfall was distributed uniformly over the surface of the model, the difference in terms of the size of scanning curves still occurred since the infiltrated water flowed along the fine sand and accumulated at the lower part of the slope model, resulting in the larger changes in matric suctions and volumetric water content in the lower part of the slope model.

\section{Scanning Curves of Silty Sand}

Another three sets of scanning curves measured on the silty sand are presented in Fig. 10. The intensities and durations of the simulated rainfall applied in the experiments were similar to those applied in the experiments on the fine sand (Fig. 8). However, the data plotted in Fig. 10 were taken from measurements with a time interval of 10 minutes.

Unlike the scanning curves measured for the fine sand, the scanning curves measured for the silty sand were only in a form of horizontal paths between the primary wetting and the primary drying soil-water characteristic curves. This happened since the volumetric water contents of the silty sand did not change during the twentyfour hour simulation. The scanning curves moved from the primary drying curve to the primary wetting curve during the application of rainfall (i.e., adsorption process) and returned to the primary drying curve again after 19 hours of drainage (see Fig. 10).

In order to obtain a full-loop scanning curve for the silty sand, one additional series of unsteady-state infiltration tests was conducted. Prior to this additional test, the slope model was left under ambient condition for about 50 days to achieve a relatively dry condition in the silty sand. The rainfall loadings in this test were also reduced (i.e., by reducing the duration of the simulated rainfall to 1 hour) to maintain a low degree of saturation of the silty sand. There were four infiltration stages involved in the additional test. In the first stage, the intensity of the rainfall applied was $9.9 \mathrm{~mm} / \mathrm{h}$ and followed by a 3 days draining process. In the second, third and fourth stages, the intensities of the applied rainfalls were $11.1,10.3$ and $69.0 \mathrm{~mm} / \mathrm{h}$, respectively, followed by 7 days of drainage. Figure 11 illustrates the program adopted in the additional series of infiltration tests.

The scanning curves obtained from the additional series of unsteady-state infiltration tests are presented in Fig. 12. The time interval used was 10 minutes. The matric suction and volumetric water content data were taken from the readings of tensiometer $\mathrm{T}-14$ and TDR-12, respectively. The scanning curves at location $T$ (see Fig. 7) was not available since the matric suctions observed in this part of the model were beyond the range 


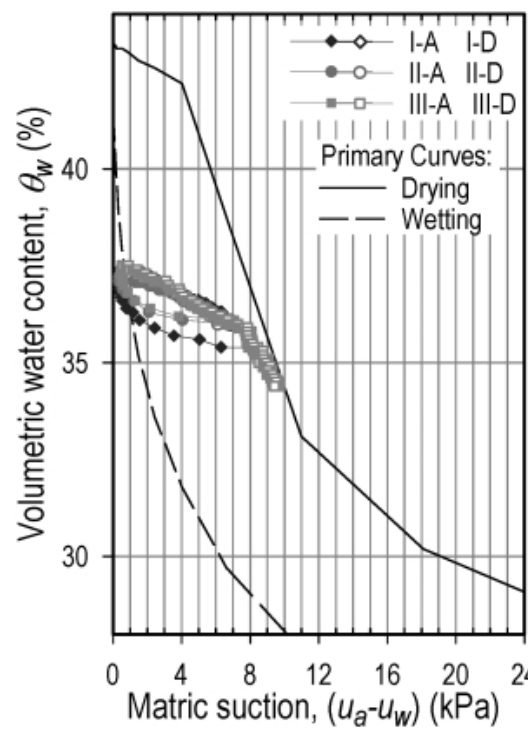

(a) at bottom part of the model (location B)

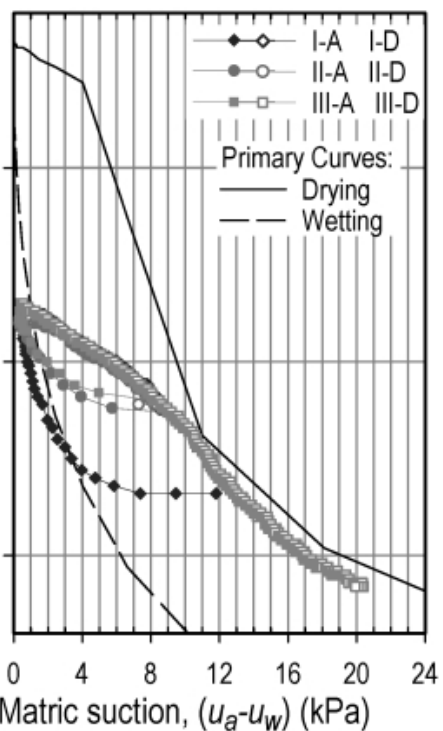

(b) at middle part of the model (location M)

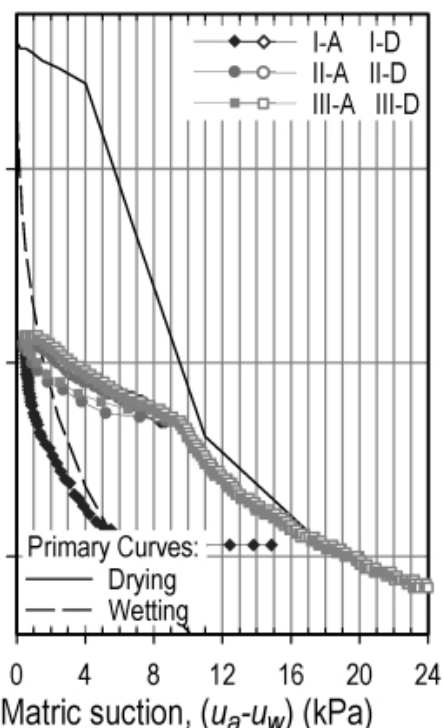

(c) at top parts of the model (location T)

Fig. 10. Primary soil-water characteristic and scanning curves measured in the silty sand during the second infiltration test series (I, II, III indicate the stages, while $A$ and $D$ indicate adsorption and desorption, respectively)

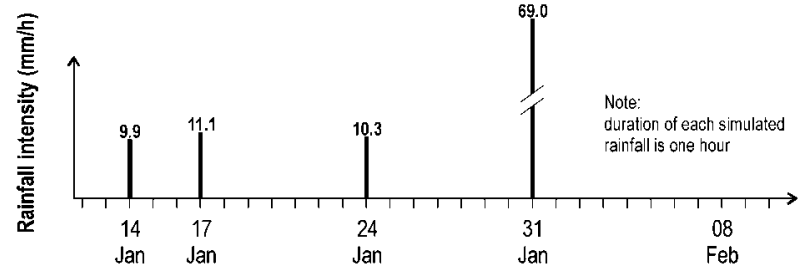

Fig. 11. Experimental program adopted in the additional unsteadystate infiltration test series

of measurement of the tensiometer (i.e., greater than 100 $\mathrm{kPa}$ ). Similarly, the scanning curves at locations $\mathrm{M}$ and $\mathrm{B}$ were not complete, since the suctions in the middle and top parts of the slope model were also relatively high after a long period of drainage and could not be measured (cavitations in the tensiometer) in most of the experiments.

As can be seen in Fig. 12, the scanning curve started from the drying primary curve since the model experienced drying prior to the experiments. During the application of the simulated rainfall in the first stage (dated $14 \mathrm{Jan}$ ), there was no significant changes in both matric suction and volumetric water content. However, after the simulated rainfall ended, it was observed that the matric suction started to decrease and the volumetric water content to increase, resulting in the scanning curve developing a path from the drying primary curve to the wetting primary curve (even though there was no rainfall applied). The delay in the development of the scanning curve was due to the time needed by the infiltrating water to flow from the surface of the slope model to the location of the instrumentations.

In terms of the shape, the scanning curves from the

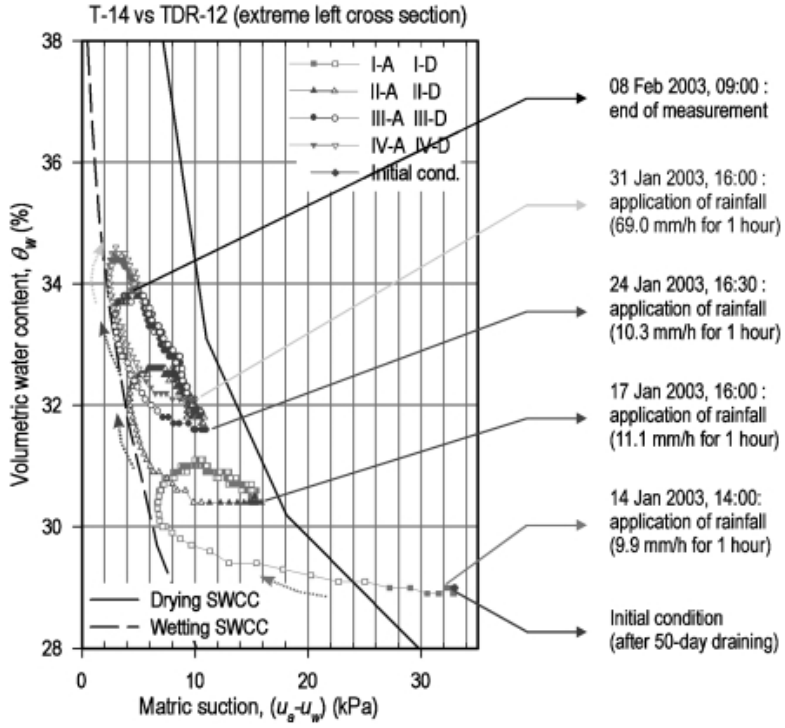

Fig. 12. Scanning curves from the results of the additional unsteadystate infiltration the series measured in the silty sand (I, II, III, IV indicate the stages, while $A$ and $D$ indicate adsorption and desorption, respectively)

additional series of tests (Fig. 12) were found to have different shapes compared with the scanning curve from the typical infiltration test. Unlike the scanning curves presented in Figs. 9 and 10, where the volumetric water content decreased once the matric suction increased, the scanning curves shown in Fig. 12 had a different shape (i.e., 'humpy' shape), since the volumetric water content of the silty sand kept increasing although its matric suction started to increase. This observation was suspected to be due to the different mechanisms (i.e., adsorption and desorption) experienced by the soil sur- 
rounding tensiometer $\mathrm{T}-14$ compared with those experienced by the soil surrounding TDR-12 (Fig. 7). The matric suction as recorded by Tensiometer T-14 was recovered (i.e., increased) after the infiltrating water from the surface of the model flowed and passed the tensiometer tip. However, the volumetric water content of the soil surrounding TDR-12 still increased, due to lateral drainage from the upper part of the slope model. The water from lateral drainage did not pass tensiometer $\mathrm{T}-14$ since its location was in the extreme left of the slope model (see Fig. 7) and the water from lateral drainage flowed to the drainage outlet at the bottom of the slope model. The volumetric water content measured by TDR-12 decreased again (i.e., recovered) once there was no more water flow from lateral drainage, and as a result the scanning curve began to follow the path of the primary drying curve.

The effect of lateral drainage as discussed above appears to be due to the initial dry condition of the silty sand. If the initial condition of the silty sand was relatively wet (see Fig. 10), the 'hump' shape of the curve would not occur, even when the duration of the rainfall was short (e.g., 1 hour). When the initial condition of the silty sand was relatively wet, the water phase in the soil voids was continuous, and as a result the matric suction decreased once rainfall was applied. In addition, the effect of lateral drainage on the shape of the scanning curves would not exist if both the tensiometer and TDR were at the same location. In this case, the scanning curves would be similar to those presented in Fig. 10.

The same scanning curve trend was also observed in the other stages conducted in the additional series of infiltration test (Stages II, III and IV). It should be noted that the intensity of the simulated rainfall applied in the fourth stage was significantly higher than that applied in the first three stages. However, the amount of water infiltrating into the model remained the same, since the additional water from the simulated rainfall was transformed into runoff.

As was mentioned earlier, the scanning curve followed the primary wetting curve of the soil-water characteristic curve even though the simulated rainfall had ended. This observation indicated that the path of the scanning curve during the experiment did not depend on the flux boundary applied to the slope model (i.e., precipitation or evaporation), but on the process exhibited by the soils (i.e., adsorption or desorption). During adsorption, the scanning curve followed the primary wetting soil-water characteristic curve, while during desorption, the scanning curve followed the primary drying soil-water characteristic curve.

Error in Estimation of Scanning Curves due to the Different Locations of Tensiometer Tips and TDR WaveGuides

The scanning curves presented in this paper were constructed from the matric suction and the volumetric water content data that were measured at the same time but at slightly different locations. In order to quantify the

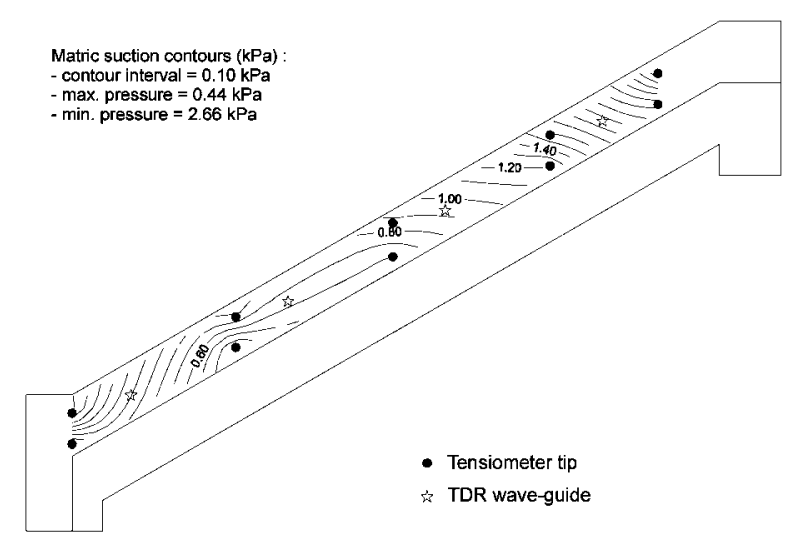

(a) at wet condition (i.e., end of Test II-A)

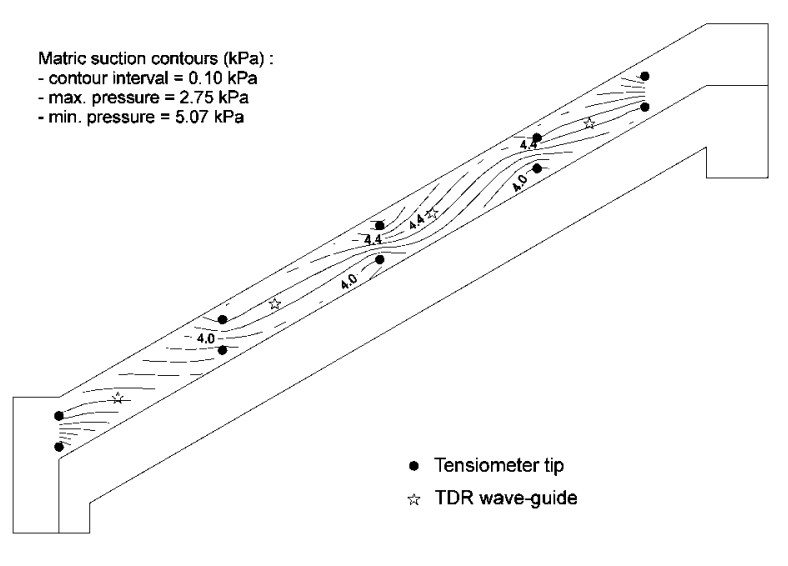

(b) at dry condition (i.e., end of Test III-D)

Fig. 13. Matric suction contours measured in the fine sand

magnitude of the errors that could be involved in the construction of the scanning curves due to the different measurement locations, the matric suction data were contoured and the magnitude of the matric suctions at the exact locations of the volumetric water content measurements were estimated from the matric suction contours. Using the same technique, the magnitude of the volumetric water contents at the exact location of matric suction measurements could also be estimated by contouring the volumetric water content data. However, since the number of measurement locations of matric suction was larger than the number of measurement locations of volumetric water content, the matric suction data were selected to be contoured rather than the volumetric water content data. The matric suction contours were created using the computer program, Surfer ${ }^{\circledR}$ Ver.6 (Golden Software Inc., 1997).

Two sets of matric suction contours were created for each soil; one represented a dry condition and the other represented a wet condition. The measurement data used to construct the matric suction contours at the wet condition was taken at the end of Stage II-A (indicated by point $\mathbf{X}$ in Fig. 9), while those used to construct the matric suction contours at the dry condition were taken from the end of Stage III-D (indicated by point $\mathbf{Y}$ in Fig. 9). Figure 13 presents the contours of matric suctions measured in the fine sand, while Fig. 14 presents the 


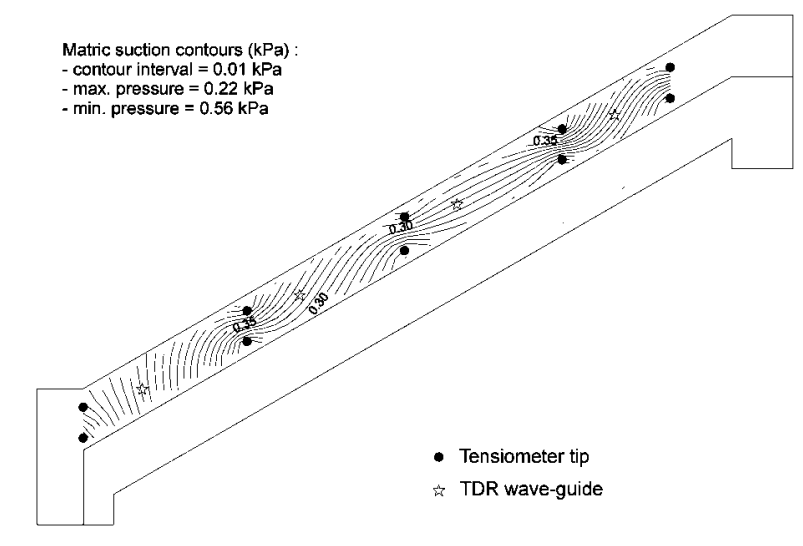

(a) at wet condition (i.e., end of Test II-A)

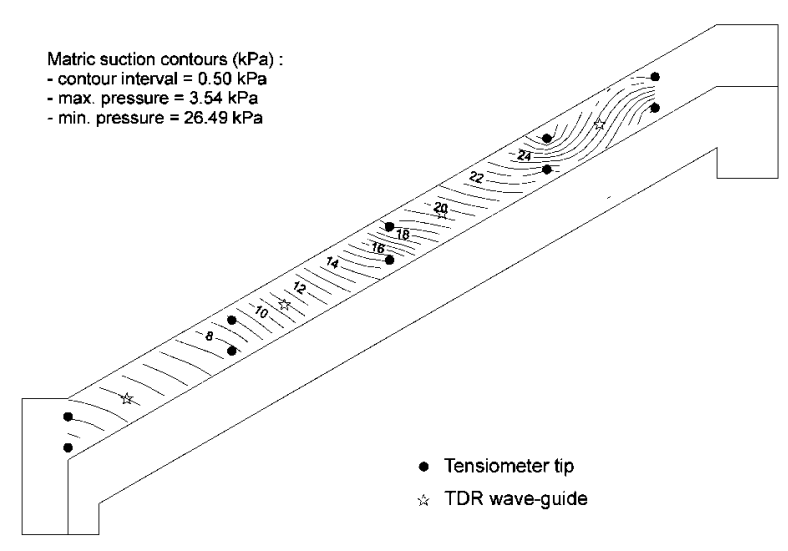

(b) at dry condition (i.e., end of Test III-D)

Fig. 14. Matric suction contours measured in the silty sand

contours of matric suction measured in the silty sand.

The matric suction contours shown in Figs. 13(a), 13(b) and 14(a) have a small range between their maximum and minimum values, indicating that the matric suction distributions within the slope model were relatively uniform. However, this was not the case in Fig. 14(b), where the differences between the maximum and minimum values were quite significant. It was also observed from the experimental data that the gradient in matric suction was large in Fig. 14(b), indicating that the silty sand was still experiencing drainage. In other words, the matric suctions in Fig. 14(b) were still changing, however the rate of matric suction or volumetric water content changes was relatively small.

From Figs. 13 and 14, the matric suctions at the locations of the TDR wave-guides could be estimated. The matric suctions obtained from the contours (i.e., Figs. 13 and 14) were then compared with those measured by the tensiometers (i.e., used to create the scanning curves). By comparing these matric suction data (as shown in Table 2), the magnitude of errors involved in the matric suction data used to create the scanning curves due to the different locations of the tensiometer tips and TDR wave-guides can be estimated and quantified.

As can be seen from Table 2, the difference in magnitude of matric suction (in $\mathrm{kPa}$ ) obtained from the different methods was relatively insignificant. The
Table 2. Differences in matric suction data between those measured by the tensiometer and those estimated from the matric suction contours

\begin{tabular}{|c|c|c|c|c|c|}
\hline \multirow[b]{2}{*}{$\begin{array}{l}\text { Soil } \\
\text { type }\end{array}$} & \multirow[b]{2}{*}{$\begin{array}{c}\text { Soil } \\
\text { condition }\end{array}$} & \multirow[b]{2}{*}{$\begin{array}{l}\text { Location } \\
\text { (see Fig. 8) }\end{array}$} & \multicolumn{3}{|c|}{ Matric suctions $(\mathrm{kPa})$} \\
\hline & & & $\begin{array}{c}\text { Measured } \\
\text { by } \\
\text { tensiometer }\end{array}$ & $\begin{array}{l}\text { Estimated } \\
\text { from the } \\
\text { contours }\end{array}$ & Differences \\
\hline \multirow{6}{*}{$\begin{array}{l}\text { Fine } \\
\text { sand }\end{array}$} & \multirow{3}{*}{ at wetting } & B & 0.81 & 0.65 & 0.16 \\
\hline & & M & 0.88 & 0.95 & 0.07 \\
\hline & & $\mathrm{T}$ & 1.59 & 1.85 & 0.26 \\
\hline & \multirow{3}{*}{ at drying } & B & 4.26 & 4.15 & 0.11 \\
\hline & & M & 4.73 & 4.40 & 0.33 \\
\hline & & $\mathrm{T}$ & 4.53 & 4.45 & 0.08 \\
\hline \multirow{6}{*}{$\begin{array}{l}\text { Silty } \\
\text { sand }\end{array}$} & \multirow{3}{*}{ at wetting } & B & 0.40 & 0.34 & 0.06 \\
\hline & & M & 0.33 & 0.30 & 0.03 \\
\hline & & $\mathrm{T}$ & 0.40 & 0.32 & 0.08 \\
\hline & \multirow{3}{*}{ at drying } & B & 8.91 & 10.80 & 1.89 \\
\hline & & M & 18.75 & 19.60 & 0.85 \\
\hline & & $\mathrm{T}$ & 24.49 & 24.00 & 2.49 \\
\hline
\end{tabular}

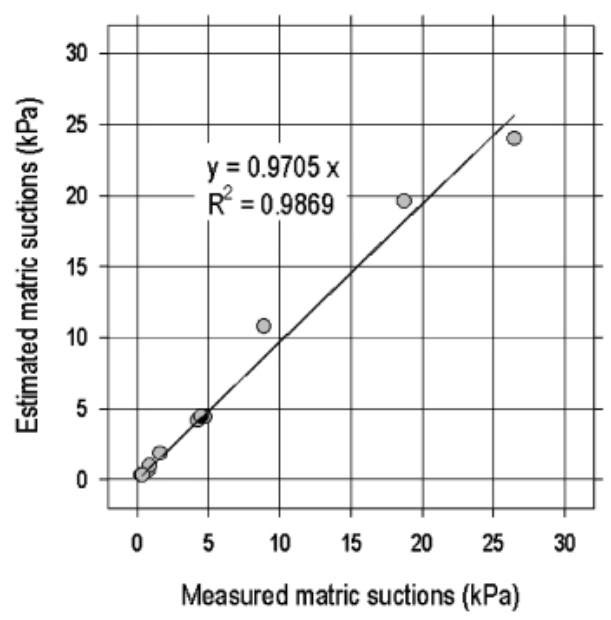

Fig. 15. Comparison of matric suctions, between measured and estimated data (refer to Table 2)

comparison of matric suctions measured by the tensiometers and those estimated from the contours are presented in Fig. 15. The resulting scanning curves would be in the same region and would have the same shape as shown in Figs. 9, 10 and 12, when the matric suction data were corrected according to Table 2 .

\section{Effect of Fine Content on Scanning Curves}

Figure 16 presents the scanning curves for both fine sand and silty sand measured at the middle of the slope model (i.e., point $\mathrm{M}$ ). The matric suction and volumetric water content data were obtained from tensiometer T-34 and TDR-52, respectively. The infiltration tests used to obtain both scanning curves were also the same (Fig. 8). The primary drying and primary wetting curves of the soil-water characteristic curve are also shown in Fig. 16. Similar observations were found when comparing the scanning curves at the bottom and top part of the slope model (i.e., points $\mathrm{T}$ and $\mathrm{B}$ ).

For the matric suction ranges observed during the experiments, the changes in volumetric water contents 


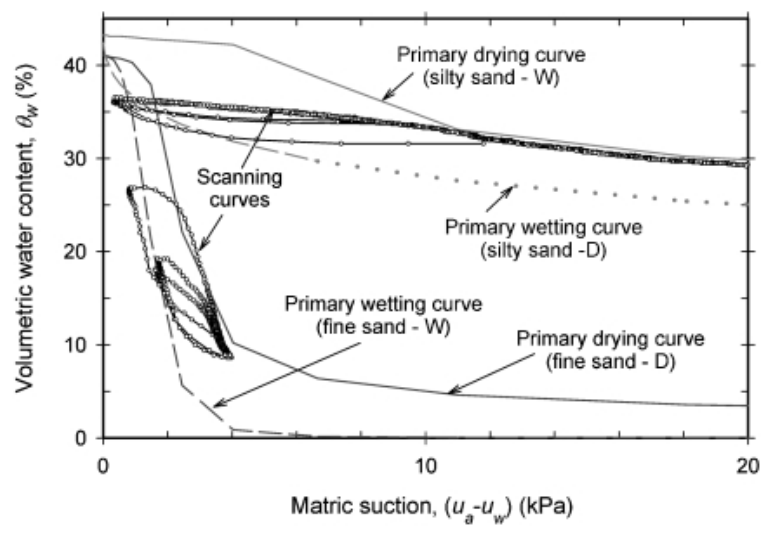

Fig. 16. Comparison of scanning curves measured on silty sand and fine sand (from experimental data at location of point $M$ )

observed in the fine sand were significant as compared than those observed in the silty sand. This difference was due to the difference in the amount of free water in the soil skeleton. Free water is the soil water that can be removed from the soil by applying a difference in total head or a hydraulic gradient. For a specific volume of soil, the amount of free water in the fine sand was larger than that in the silty sand.

Unlike the changes in volumetric water content, changes in matric suction observed in the silty sand had a larger range compared with those in the fine sand. In other words, the changes in matric suction were more sensitive to changes in volumetric water content in finegrained soils compared with those in coarse-grained soils, especially in the high water content/low suction regime. This is due to the fact that in the low suction regime, where the soil has a high volumetric water content, the water phase in the soil skeleton was continuous. As a result, an increase or a decrease in pressure from the infiltrating water will be transferred directly to a change in matric suction of the soil.

From the above observation, for the matric suction ranges observed during the experiments, it can be concluded that a small change in the volumetric water content of the fine-grained soil does not mean that the matric suction does not change significantly. On the other hand, a small change in the matric suction in the coarsegrained soil does not mean that the volumetric water content does not change significantly.

In terms of the water storage capacity of the soils, it was observed that the longer the scanning curves formed during infiltration, the larger the amount of water adsorbed by the soil. During the twenty-four hour simulation, the scanning curves of the silty sand only moved between the primary drying and the primary wetting curves in an almost horizontal direction, indicating small changes in the volumetric water content of the silty sand. This observation was consistent with the water balance measurement, where most of the rainfall applied was transformed into runoff in the silty sand. On the other hand, the scanning curves observed for fine sand did not only move between the primary drying and the primary wetting curves, but also moved along the primary wetting curve during adsorption and along the primary drying curve during desorption. This observation was consistent with the water balance measurement, and there was no runoff observed in the experiment. In this case, all rainfall was transferred to infiltration.

Numerical methods such as the finite element or finite difference techniques have become a necessary tool for solving infiltration problems. Numerical analyses are usually preformed using the drying soil-water characteristic curve, because the soil-water characteristic curve is commonly determined following a drying process. In the case, where both drying and wetting soil-water characteristic curves are available, numerical analysis of the infiltration process employs the wetting soil-water characteristic curve while the drying soil-water characteristic curve is used to simulate evaporation.

By examining the scanning curves obtained from the experimental data presented in this paper, the use of drying or wetting soil-water characteristic curves in the modelling of water flow in unsaturated soils can be reviewed. During the adsorption process, the scanning curve followed the primary wetting soil-water characteristic curve, regardless of whether the soil was subjected to precipitation or evaporation. Similarly, during the desorption process, the scanning curve followed the primary drying soil-water characteristic curve, regardless of whether the soil was subjected to precipitation or evaporation. Therefore, the appropriate hydraulic parameters of the soils (i.e., drying or wetting) should be used according to the process that the soils actually experience (i.e., desorption process or adsorption process).

Most of the available numerical methods solve the seepage problem in terms of pressure head, and then calculate other necessary parameters, such as water content, flow rate or water storage, based on the pressure head obtained. Figure 17 illustrates the error that could take place in the calculation of the volumetric water content when the drying soil-water characteristic curve was employed in the simulation of infiltration in unsaturated soils. For the same matric suction changes (initial condition at point $\mathbf{O}$ ), the volumetric water contents measured using the drying soil-water characteristic curve (indicated by point $\mathbf{Q}$ ) were significantly higher compared with those measured using the scanning curve (point $\mathbf{P}$ ). The error in the calculation of the volumetric water content will lead to an error in the calculation of the water balance.

\section{CONCLUSIONS}

The scanning curves and the primary soil-water characteristic curves of two soils (i.e., silty sand and fine sand) have been presented in this paper. It was found that the scanning curves followed the primary wetting curve during the adsorption process and then followed the primary drying curve during the desorption process. During the transition between the two primary curves (i.e., drying and wetting), the scanning curve had a rela- 


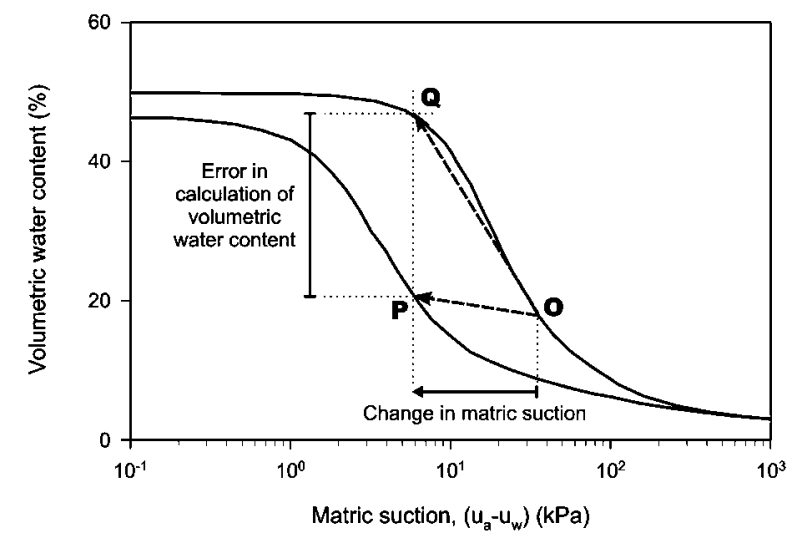

Fig. 17. Idealized path of soil-water characteristic curve used in the numerical simulation of infiltration process (decrease in matric suction)

tively flat slope compared with the slope of the primary curves, and sometimes it was almost horizontal. However, the slope and path of the scanning curves were found to be similar for the cases with similar initial conditions.

It was observed from the scanning curve of the fine sand that a small change in matric suction can cause a significant change in water content. On the other hand, a large change in the matric suction in the silty sand might not change its water content significantly.

\section{ACKNOWLEDGMENT}

The work described is supported by research grant No. RG7/99 from Nanyang Technological University, Singapore. The first author acknowledges the discussion and the advice given by Prof. D. G. Fredlund from the University of Saskatchewan, Canada, especially at the beginning of the study, and also the research scholarship from the Nanyang Technological University, Singapore.

\section{REFERENCES}

1) ASTM D 2325-68. (1994): Standard Test Method for Measurement of Moisture Characteristic Curve Using a Tempe Cell, Annual Book of ASTM Standards, 04.08, Soil and Rock. American Society for Testing and Materials (ASTM), Philadelphia, Pa.

2) Braddock, R. D., Parlange, J.-Y. and Lee., H. (2001): Application of a soil water hysteresis model to simple water retention curves, Transport in Porous Media, 44, 407-420.

3) Brooks, R. H. and Corey, A. J. (1964): Hydraulic properties of porous media, Hydrology Paper 3, Colorado State University, Fort Collins, CO, 1-27.

4) Feng, M. and Fredlund, D. G. (1999): Hysteretic influence associated with thermal conductivity sensor measurements, Proc. from Theory to the Practice of Unsaturated Soil Mechanics, in association with 52nd Canadian Geotechnical Conference \& Unsaturated Soil Group, Regina, 14:2:14-14:2:20.

5) Fredlund, D. G. and Rahardjo, H. (1993): Soil Mechanics for Unsaturated Soils, New York, John Wiley and Sons Inc.
6) Fredlund, D. G. and Xing, A. (1994): Equations for the soil-water characteristic curve, Can. Geotech. J., 31 (3), 521-532.

7) Golden Software Inc. (1997): User's Guide for Surfer ver.6, Golden, CO.

8) Hogarth, W. L., Hopmans, J., Parlange, J.-Y. and Haverkamp, R. (1988): Application of a simple soil-water hysteresis model, Journal of Hydrology, 98, 21-29.

9) Iwata, S., Tabuchi, T. and Warkentin, B. P. (1995): Soil-Water Interactions, New York, Marcel Dekker, Inc.

10) Lambe, T. W. (1951): Soil Testing for Engineers, New York, John Wiley and Sons Inc.

11) Leong, E. C. and Rahardjo, H. (1997): Review of soil-water characteristic curve equations, Geotech. Geoenviron. Engrg., ASCE, 123 (12), 1106-1117.

12) Liu, Y., Parlange, J.-Y., Steenhuis, T. S. and Haverkamp, R. (1995): A soil-water hysteresis model for fingered flow data, Water Resources Research, 31, 2263-2266.

13) Mualem, Y. (1974): A conceptual of hysteresis, Water Resources Research, 12, 514-520.

14) Nimmo, J. R. and Miller, E. E. (1986): The temperature dependence of isothermal moisture vs potential characteristics of soils, Soil Science Society America Journal, 50, 1105-1113.

15) Parlange, J.-Y. (1976): Capillary hysteresis and relationship between drying and wetting curves, Water Resources Research, 12 (2), 224-228.

16) Pham, H. Q., Fredlund, D. G. and Barbour, S. L. (2003): A practical hysteresis model for the soil-water characteristic curve for soils with negligible volume change, Geotechnique, 53 (2), 293-298.

17) Poulovassilis, A. (1970): Hysteresis of pore water in granular porous bodies, Journal of Soil Science, 109 (1), 5-12.

18) Poulovassilis, A. and Childs, E. C. (1971): The hysteresis of pore water: the non-independence of domains, Journal of Soil Science, 112 (5), 301-312.

19) Public Works Department (1976): The Geology of the Republic Singapore, Singapore.

20) Rahardjo, H. (2000): Rainfall induced slope failures, NSTB Rep. $17 / 6 / 16$, School of Civil and Structural Engineering, Nanyang Technological Univ., Singapore.

21) Si, B. C. and Kachanoski, R. G. (2000): Unified solution for infiltration and drainage with hysteresis; theory and field test, Soil Science Society America Journal, 64, 30-35.

22) Soilmoisture Equipment Corp. (1996): Operating Instruction for Trase BE 6050X1, Santa Barbara, CA.

23) Talsma, T. (1970): Hysteresis in two sands and the independent domain model, Water Resources Research, 15, 95-102.

24) Tami, D., Rahardjo, H., Leong, E. C. and Fredlund, D. G. (2004): A physical model for capillary barriers, Geotech. Test. J., 27 (2), 173-183.

25) Topp, G. C. (1971): Soil water hysteresis in silt loam and clay loam soils, Water Resources Research, 7 (4), 914-920.

26) Topp, G. C. and Miller, E. E. (1966): Hysteresis moisture characteristics and hydraulic conductivities for glass-bead media, Soil Science Society America Proc., 30, 156-162.

27) Vachaud, G. and Thony, J.-L. (1971): Hysteresis during infiltration and redistribution in a soil column at different initial water content, Water Resources Research, 7 (1), 111-127.

28) van Genuchten, M. Th. (1980): A closed form equation for predicting the hydraulic conductivities of unsaturated soils, Soil Science Society America Journal, 44, 892-898.

29) Viaene, P., Vereecken, H., Diels, J. and Feyen, J. (1994): A statistical analysis of six hysteresis models for the moisture retention characteristic, Soil Science, 157, 345-355.

30) Watson, K. K., Reginato, R. J. and Jackson, R. D. (1975): Soil water hysteresis in a field soil, Soil Science Society America Proce., 39 (2), 242-246. 